\title{
Metanálisis: la glucosamina y el condroitín podrian ser efectivos en la osteoartritis
}

Glucosamine and Chondroitin for Treatment of Osteoarthritis. A systematic Quality Assesment and Meta-analysis. McAlindon TE, La Valley MP, Gulin JP, Felson DT. JAMA. 2000; 283(11):1469-75.

\section{Objetivo}

Evaluar el efecto de los preparados de glucosamina y condroitín para aliviar los síntomas de osteoartritis $(O A)$ de rodilla y /o cadera.

\section{Diseño}

Metaanálisis combinado con una evaluación de calidad sistemática de ensayos clínicos que utilizaron éstas preparaciones.

\section{Fuente y selección de datos}

Realizaron una búsqueda en MEDLINE (1966 a Junio de 1999) y en el Registro Cochrane de Ensayos Clínicos usando los términos osteoarthritis, osteoarthrosis, degenerative arthritis, glucosamine, chondroitin and glycosamynoglycans. También revisaron artículos de revisión mediante búsqueda manual, manuscritos, suplementos de reumatología, revistas de $0 \mathrm{~A}$ y datos no publicados, mediante el contacto con expertos, autores de estudios y fabricantes de glucosamina y condroitín.

Se incluyeron en el análisis estudios publicados y no publicados que hayan evaluado la glucosamina y el condroitín para el tratamiento sintomático de $0 \mathrm{~A}$ de rodilla y / o cadera; que tuvieran una duración de 4 semanas o más. El diseño de los mismos fue doble ciego, aleatorizado y controlado con placebo. Quince de los 37 estudios encontrados cumplieron los criterios de inclusión.

\section{Extracción de los datos}

Los revisores calificaron a los estudios con un instrumento para evaluar calidad, definieron un tamaño del efecto en base a los resultados de los estudios (el mismo se calculaba según la diferencia promedio entre los grupos al final del estudio, y se la dividía por el desvío estándar del resultado en el grupo placebo). Así, un efecto de 0.2 fue considerando como pequeño, 0.5 mediano y 0.8 un efecto grande. Aplicaron un factor de corrección para reducir sesgos* y estratificaron los estudios por calidad y tamaño, evaluando la heterogeneidad* y sesgos de publicación*.

Resultados principales

El rango de calidad fue de $12.3 \%$ a $55.4 \%$ del máximo puntaje posible, con una media de $35.5 \%$. Solo un estudio describió un adecuado ocultamiento de la asignación del tratamiento* (allocation concealment en inglés) y dos reportaron un análisis por intención de tratar*. Muchos fueron realizados o financiados por los fabricantes de los productos. La evaluación mostró la probable presencia de un sesgo de publicación. El test de heterogeneidad no fue significativo luego de retirar un ensayo extremo. El tamaño del efecto promedio en los estudios analizados fue de 0.44 (IC $95 \% 0.24$ a 0.64 ) para glucosamina y 0.78 (IC $95 \% 0.60$ a 0.95 ) para condroitin, pero estos fueron menores cuando se analizaron solo los estudios de alta calidad y tamaño muestral. El tamaño del efecto fue relativamente consistente tanto para el dolor como para la funcionalidad articular.

\section{Conclusiones}

Los estudios con glucosamina y condroitín para el tratamiento sintomático de $0 \mathrm{~A}$ demostraron un efecto moderado a grande, pero la calidad y los sesgos de selección encontrados en el análisis sugieren que estos resultados son exagerados. Sin embargo, algún grado de eficacia parece existir con estas preparaciones.

\section{COMENTARIO}

La osteoartritis o artrosis es uno de los problemas de salud pública más importante en la actualidad, sin embargo existen pocas medidas efectivas para su tratamiento. Las indicaciones más aconsejadas son educación, soporte social, control del peso, ejercicio y tratamiento del dolor. El tratamiento más indicado por la comunidad médica es antiinflamatorios no esteroideos (AINEs) por vía sistémica, sin priorizar el uso del paracetamol, cremas locales (como capsaicina) y la infiltración con corticoides cuando existe edema intraarticular. Por esta razón la $0 \mathrm{~A}$ está ligada a otro problema de salud pública que es la morbimortalidad causada por AINEs, tanto en el compromiso gastrointestinal como renal.

En este contexto es interesante la búsqueda de tratamientos farmacológicos más seguros para tratar de aliviar el dolor y permitir una me- jor función de la articulación afectada por OA.

Este es un metaanálisis realizado con recursos financieros independientes y su diseño fue muy prolijo en cuanto a la búsqueda y selección de los estudios que analizaron. Aún así los 15 trabajos incluidos tuvieron problemas metodológicos que sobrestimaron el efecto beneficioso de la glucosamina y condroitín, para el tratamiento sintomático de la OA. Sin embargo, el efecto beneficioso parece existir y podría ser utilizado en pacientes con OA. Un punto importante a destacar es que el costo promedio mensual del tratamiento con glucosamina y condroitín es elevado (de aprox. $\$ 100$ y $\$ 70$ respectivamente en Argentina). Los autores de este estudio recomiendan realizar estudios independientes, de alta calidad para determinar la eficacia y utilidad de estas preparaciones a corto y largo plazo.

*Ver glosario

Dr. Ricardo Frusso

Unidad de Medicina Familiar y Preventiva. Hospital Italiano de Buenos Aires 